\title{
New Prime Factorization Algorithm and Its Parallel Computing Strategy
}

\author{
Lican Huang ${ }^{1,2}$ \\ ${ }^{1}$ School of Informatics, Zhejiang Sci-Tech University \\ ${ }^{2}$ Hangzhou Domain Zones Technology Co., Ltd \\ Hangzhou, China \\ Huang_lican@yahoo.co.uk
}

\begin{abstract}
Prime factorization is vital important for mathematics and RSA security system. In this paper we present a new algorithm to factorize numbers and a new parallel strategy for prime factorization, which may be help to find the fault of RSA system and design more safe RSA keys, and to arise the discussion about the safety of RSA security system.
\end{abstract}

Keywords-Distribted Computation; prime factorization; parallel computing

\section{INTRODUCTION}

Prime factorization or integer factorization of a number is the determination of the set of prime numbers which multiply together to give the original integer. It is also known as prime decomposition. Prime factorization is vital important because RSA [1] security system is based on it. For prime factorization, polynomial time factoring algorithm on classical computers has been not found yet, however, P. Shor [4] presented a polynomial time algorithm on quantum computers. Of course, quantum computers have been not made yet, and we do not know when they are made. As for classical computations, there are several prime factorization algorithms presented such as Quadratic Sieve (QS) [5], Number Field Sieve (NFS)[2], Pollard's $p-1$ method [3] , H. C. Williams's p+1 method [6], etc. There are also parallel computing methods to solve factor factorization problem such as using hadoop[7]. However, for big numbers, factorization is hard to get. In this paper, we present a novel method which constructs suitable solution tree by modulo and prunes search branches by equations set and other methods such random, and we also present a parallel strategy by using huge number of nodes.

The remainder of this paper is organized as follows: section II gives new algorithm of prime factorization; section III gives distributed parallel strategy of prime factorization; section IV presents implementation of the algorithm; finally we give conclusions.

\section{NeW Algorithm OF PRIME FACTORIZATION}

For number system base as $\mathrm{s}$, number $\mathrm{N}$ with $\mathrm{r}$ digits can be written as:

$$
\mathrm{N}=\mathrm{n}_{\mathrm{r}-1} \mathrm{~s}^{\mathrm{r}-1}+\mathrm{n}_{\mathrm{r}-2} \mathrm{~s}^{\mathrm{r}-1}+\ldots+\mathrm{n}_{1} \mathrm{~s}^{1}+\mathrm{n}_{0}
$$

Suppose $\mathrm{N}$ can be factorized as A with $\mathrm{p}$ digits for base $\mathrm{s}$, and $\mathrm{B}$ with $\mathrm{q}$ digits for base $\mathrm{s}$, that is;

$$
\begin{aligned}
& \mathrm{N}=\mathrm{A} \times \mathrm{B} \equiv\left(\mathrm{a}_{\mathrm{p}-1} \mathrm{~s}^{\mathrm{p}-1}+\underset{\mathrm{q}-2}{\mathrm{a}^{2}} \mathrm{~s}^{\mathrm{p}-1}+\ldots+\mathrm{a}_{1} \mathrm{~s}^{1}\right. \\
+ & \left.\mathrm{a}_{0}\right) \times\left(\mathrm{b}_{\mathrm{q}-1} \mathrm{~s}+\mathrm{b}_{\mathrm{q}-2} \mathrm{~s}^{\mathrm{q}-1}+\ldots+\mathrm{b}_{1} \mathrm{~s}^{1}+\mathrm{b}_{0}\right) \\
\equiv & \mathrm{a}_{\mathrm{p}-1} \mathrm{~b}_{\mathrm{q}-1} \mathrm{~s}^{\mathrm{p}+\mathrm{q}-2}+\cdots+\left(\mathrm{a}_{0} \mathrm{~b}_{2}+\mathrm{a}_{1} \mathrm{~b}_{1}+\mathrm{a}_{2} \mathrm{~b}_{0}\right) \mathrm{s}^{2}+\left(\mathrm{a}_{0} \mathrm{~b}_{1}\right. \\
+ & \left.\mathrm{a}_{1} \mathrm{~b}_{0}\right) \mathrm{s}^{1}+\mathrm{a}_{0} \mathrm{~b}_{0} \\
\equiv & \sum_{k=0 . \mathrm{p}+\mathrm{q}-2}\left(\sum_{i+j=k} \mathrm{a}_{\mathrm{i}} \mathrm{b}_{\mathrm{j}}\right) \mathrm{s}^{\mathrm{k}}
\end{aligned}
$$

The algorithm has two parts:

1. First part: Calculate all combination pairs which satisfy the modulo of the digits.

In the beginning, we calcite out all pairs which satisfies

$\mathrm{a}_{0} \mathrm{~b}_{0} \equiv \mathrm{n}_{0} \bmod \mathrm{s}$;

for each pair $\left(a_{01}, b_{01}\right)$ satisfies (3), $c_{01}$ is the carry of pair $\left(\mathrm{a}_{01}, \mathrm{~b}_{01}\right)$.

Then we can calculate all pairs which satisfies from $\mathrm{k}$

$=1$ to $\mathrm{k}=1 \cdots \mathrm{r}-1 / 2$.

$\left.\sum_{i+j=k} \mathrm{a}_{\mathrm{i}} \mathrm{b}_{\mathrm{j}}\right) \mathrm{s}^{\mathrm{k}}+\mathrm{C}_{\mathrm{kl}} \equiv \mathrm{n}_{\mathrm{k}} \bmod \mathrm{s} \quad \mathrm{k}=1 \cdots \mathrm{r}-1 / 2$

In this case, because we already suppose the $a_{i} b_{j}$ except $a_{0} b_{k}$ and $a_{k} b_{0}$, the only two $a_{k}, b_{k}$ are to be determined . We calculate all pairs which satisfy (4).

In first part the partial of $\mathrm{A}$ and $\mathrm{B}$ are equal length. We check if the partial of $\mathrm{A}$ and $\mathrm{B}$ are factors of $\mathrm{N}$. If they are 
factors, then end. If they are not factors, then go to second part.

2. Second part : for each partial of $\mathrm{A}$ and $\mathrm{B}$ from digit length $\mathrm{k}(\mathrm{k}=1 \quad \ldots, \mathrm{r}-1 / 2)$, first we suppose A's digit length is $k$, then we can calculate $B$ 's digit length $\mathrm{k}+\mathrm{m}(\mathrm{m}=1 \ldots \mathrm{r}-2-\mathrm{k})$ which satisfy (5) from $\mathrm{m}$ $=1$.

$\left.\sum_{i+j=k^{*}+m} \mathrm{a}_{\mathrm{i}} \mathrm{b}_{\mathrm{j}}\right) \mathrm{s}^{\mathrm{k}+\mathrm{m}}+\mathrm{C}_{(\mathrm{k}+\mathrm{m}) 1} \equiv \mathrm{n}_{\mathrm{k}+\mathrm{m}} \bmod \mathrm{s} \quad \mathrm{m}=1 \cdots \mathrm{r}-$ $2-\mathrm{k}, \quad \mathrm{i}=0 \cdots \mathrm{k}) \quad(5)$

We check if $A$ and $B$ with $k+1$ digit length are factors of $\mathrm{N}$. If they are factors, then end, else calculate B with $\mathrm{k}+2$ according (5), and check again, until $\mathrm{B}$ with $\mathrm{k}+\mathrm{r}-2-\mathrm{k}$. Then we suppose $\mathrm{B}$ with digit length $\mathrm{k}$, and calculate $\mathrm{A}$ with digit length $\mathrm{k}+\mathrm{m}(\mathrm{m}=1 \ldots \mathrm{r}-2-\mathrm{k})$ in the same way.

Because the algorithm is to find the path among the problem tree, and if we find the factors, the program ends, the computation time depends on that some paths can be pruned and the priority of search paths. In the algorithm, the computational time for the second part is constant due to no branch paths, where as in the first part of the algorithm, how to choose the sub-tree to search is much relative to the computational time.

We first check how to prune the branches of paths.

Suppose factor a with length la, and b with length $\mathrm{lb}$.

After first part of the algorithm, we already get part of a and $b$ with equal length $l p$, noted as $a_{0}$ and $b_{0}$ ( here $a_{0}$ and $\mathrm{b}_{0}$ are multi digits). We will use the following methods to check if the part of $a$ and $b$ is not the genuine part of factor $a$ and $b$ and can be pruned.

Suppose the part of $\mathrm{a}$ and $\mathrm{b}$ are genuine, then

$$
\begin{aligned}
& \left(a_{x} 10^{l p}+a_{0}\right)\left(b_{x} 10^{l p}+b_{0}\right)=N \\
& a_{x} b_{x} 10^{2 l p}+a_{0} b_{x} 10^{l p}+b_{0} a_{x} 10^{l p}=N-a_{0} b_{0}
\end{aligned}
$$

Select $n$ numbers to get module , we can get :

$$
\mathrm{a}_{\mathrm{x}} \mathrm{b}_{\mathrm{x}} \mathrm{m}_{\mathrm{i} 11}+\mathrm{b}_{\mathrm{x}} \mathrm{m}_{\mathrm{i} 10}+\mathrm{a}_{\mathrm{x}} \mathrm{m}_{\mathrm{i} 01} \equiv \mathrm{m}_{\mathrm{i} 00} \bmod \left(\mathrm{m}_{\mathrm{i}}\right)
$$$$
(\mathrm{i}=1 \ldots \mathrm{n}) \quad(8)
$$

We can write (8) as :

$$
\underset{(i=1 \ldots n)}{a_{x} b_{x} m_{i 11}+b_{x} m_{i 10}+a_{x} m_{i 01}+r_{i} m_{i}=m_{i 00}}
$$

Each (9) multiply $\mathrm{m}_{\mathrm{j} 11}$ ( except $\mathrm{i}=\mathrm{j}$ ) ; that is:

$$
\begin{aligned}
\mathrm{m}_{\mathrm{j} 11}=\mathrm{a}_{\mathrm{x}} \mathrm{b}_{\mathrm{x}} \mathrm{m}_{\mathrm{i} 11} \mathrm{~m}_{\mathrm{j} 11}+\mathrm{b}_{\mathrm{x}} \mathrm{m}_{\mathrm{i} 10} \mathrm{~m}_{\mathrm{j} 11}+\mathrm{a}_{\mathrm{x} 11} \mathrm{~m}_{\mathrm{i} 01} \mathrm{~m}_{\mathrm{j} 11}+\mathrm{r}_{\mathrm{i}} \mathrm{m}_{\mathrm{i}} \\
\mathrm{i}=1 \ldots \mathrm{n}, \quad \mathrm{j}=1 \ldots \mathrm{n} \quad \text { and } \mathrm{i} \neq \mathrm{j}
\end{aligned}
$$

Each two (10) $(\mathrm{i} \neq \mathrm{j})$ substrate ; that is:

$$
b_{\mathrm{x}}\left(\mathrm{m}_{\mathrm{i} 10} \mathrm{~m}_{\mathrm{j} 11}-\mathrm{m}_{\mathrm{i} 11} \mathrm{~m}_{\mathrm{j} 10}\right)+\mathrm{a}_{\mathrm{x}}\left(\mathrm{m}_{\mathrm{i} 01} \mathrm{~m}_{\mathrm{j} 11}-\mathrm{m}_{\mathrm{i} 11}\right.
$$

$\left.\mathrm{m}_{\mathrm{j} 01}\right) \quad+\mathrm{r}_{\mathrm{i}} \mathrm{m}_{\mathrm{i}} \mathrm{m}_{\mathrm{j} 11}-\mathrm{r}_{\mathrm{j}} \mathrm{m}_{\mathrm{j}} \mathrm{m}_{\mathrm{i} 11}=\mathrm{m}_{\mathrm{i} 00} \mathrm{~m}_{\mathrm{j} 11}-\mathrm{m}_{\mathrm{j} 00}$ $\mathrm{m}_{\mathrm{i} 11}$

That is:

$b_{\mathrm{x}}\left(\mathrm{m}_{\mathrm{i} 10} \mathrm{~m}_{\mathrm{j} 11}-\mathrm{m}_{\mathrm{i} 11} \mathrm{~m}_{\mathrm{j} 10}\right)+\mathrm{a}_{\mathrm{x}}\left(\mathrm{m}_{\mathrm{i} 01} \mathrm{~m}_{\mathrm{j} 11}-\mathrm{m}_{\mathrm{i} 11}\right.$ $\left.\mathrm{m}_{\mathrm{j} 01}\right) \quad+\mathrm{r}_{\mathrm{i}} \mathrm{m}_{\mathrm{i}} \mathrm{m}_{\mathrm{j} 11}-\mathrm{r}_{\mathrm{j}} \mathrm{m}_{\mathrm{j}} \mathrm{m}_{\mathrm{i} 11}=\mathrm{m}_{\mathrm{ij}}$

$$
\mathrm{i}=1 \ldots \mathrm{n}, \quad \mathrm{j}=1 \ldots \mathrm{n} \quad \text { and } \mathrm{i} \neq \mathrm{j}
$$
variables

We have $n(n-1) / 2$ equations as format (11) with $n+2$

We can use another method to prune branches.

$\left(a_{x} 10^{l p}+a_{0}+b_{x} 10^{l p}+b_{0}\right)^{2}-\left(a_{x} 10^{l p}+a_{0}-\right.$ $\left.b_{\mathrm{x}} 10^{\mathrm{lp}}-\mathrm{b}_{0}\right)^{2}=4 \mathrm{~N}$

$\left(\left(\mathrm{a}_{\mathrm{x}}+\mathrm{b}_{\mathrm{x}}\right) 10^{\mathrm{lp}}+\left(\mathrm{a}_{0}+\mathrm{b}_{0}\right)\right)^{2}-\left(\left(\mathrm{a}_{\mathrm{x}}-\mathrm{b}_{\mathrm{x}}\right) 10^{\mathrm{lp}}+\left(\mathrm{a}_{0}\right.\right.$ $\left.\left.-\mathrm{b}_{0}\right)\right)^{2}=4 \mathrm{~N}$

$\left(\mathrm{a}_{\mathrm{x}}+\mathrm{b}_{\mathrm{x}}\right)^{2} 10^{2 \mathrm{p}}+2\left(\mathrm{a}_{\mathrm{x}}+\mathrm{b}_{\mathrm{x}}\right) 10^{1 \mathrm{p}}\left(\mathrm{a}_{0}+\mathrm{b}_{0}\right)+\left(\mathrm{a}_{0}\right.$ $\left.+b_{0}\right)^{2}-\left(\left(a_{x}-b_{x}\right)^{2} 10^{2 l p}+2\left(a_{x}-b_{x}\right) 10^{1 p}\left(a_{0}-b_{0}\right)+\right.$ $\left.\left(\mathrm{a}_{0}-\mathrm{b}_{0}\right)^{2}\right)=4 \mathrm{~N} \quad(14)$

$$
\text { Let } \mathrm{s}=\mathrm{a}_{\mathrm{x}}+\mathrm{b}_{\mathrm{x}} ; \quad \mathrm{t}=\mathrm{a}_{\mathrm{x}}-\mathrm{b}_{\mathrm{x}} \text {; }
$$

$(\mathrm{s})^{2} 10^{2 \mathrm{p}}+2(\mathrm{~s}) 10^{\mathrm{lp}}\left(\mathrm{a}_{0}+\mathrm{b}_{0}\right)+\left(\mathrm{a}_{0}+\mathrm{b}_{0}\right)^{2}-\left((\mathrm{t})^{2} 10\right.$

$\left.{ }^{2 l p}+2(\mathrm{t}) 10^{\mathrm{lp}}\left(\mathrm{a}_{0}-\mathrm{b}_{0}\right)+\left(\mathrm{a}_{0}-\mathrm{b}_{0}\right)^{2}\right)=4 \mathrm{~N}$

$$
(\mathrm{s})^{2} 10^{2 \mathrm{lp}}+2(\mathrm{~s}) 10^{\mathrm{lp}}\left(\mathrm{a}_{0}+\mathrm{b}_{0}\right)-(\mathrm{t})^{2} 10^{2 \mathrm{p}}-2
$$

(t) $10^{\text {lp }}\left(\mathrm{a}_{0}-\mathrm{b}_{0}\right)=4 \mathrm{~N}-4 \mathrm{a}_{0} \mathrm{~b}_{0}$

$$
\left(\mathrm{s}^{2}-\mathrm{t}^{2}\right) 10^{2 \mathrm{p}}+2 \mathrm{~s} 10^{\mathrm{lp}}\left(\mathrm{a}_{0}+\mathrm{b}_{0}\right) \quad-2 \mathrm{t} 10^{\mathrm{lp}}\left(\mathrm{a}_{0}\right.
$$$$
\left.-\mathrm{b}_{0}\right) \quad=4 \mathrm{~N}-4 \mathrm{a}_{0} \mathrm{~b}_{0}
$$

Select $\mathrm{n}$ numbers to get module, we can get:

$\left(\mathrm{m}_{\mathrm{i}}\right)$

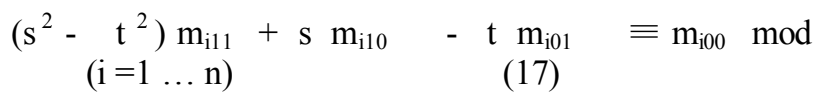

We can write (17) as :

$\left(\mathrm{s}^{2}-\mathrm{t}^{2}\right) \mathrm{m}_{\mathrm{i} 11}+\mathrm{s} \mathrm{m}_{\mathrm{i} 10}-\mathrm{t} \mathrm{m}_{\mathrm{i} 01}+\mathrm{r}_{\mathrm{i}} \mathrm{m}_{\mathrm{i}}=\mathrm{m}_{\mathrm{i} 00}$ $(\mathrm{i}=1 \ldots \mathrm{n})$

Each (18) multiply $\mathrm{m}_{\mathrm{j} 11}$ ( except $\mathrm{i}=\mathrm{j}$ ) ; that is: 
$\left(\mathrm{s}^{2}-\mathrm{t}^{2}\right) \mathrm{m}_{\mathrm{i} 11} \mathrm{~m}_{\mathrm{j} 11}+\mathrm{s} \mathrm{m}_{\mathrm{i} 10} \mathrm{~m}_{\mathrm{j} 11}-\mathrm{t} \mathrm{m}_{\mathrm{i} 01} \mathrm{~m}_{\mathrm{j} 11}+$ $\mathrm{r}_{\mathrm{i}} \mathrm{m}_{\mathrm{i}} \mathrm{m}_{\mathrm{j} 11}=\mathrm{m}_{\mathrm{i} 00} \mathrm{~m}_{\mathrm{j} 11}$

$$
\mathrm{i}=1 \ldots \mathrm{n}, \quad \mathrm{j}=1 \ldots \mathrm{n} \text { and } \mathrm{i} \neq \mathrm{j}
$$

Each two (19) $(\mathrm{i} \neq \mathrm{j})$ substrate ; that is:

$$
\mathrm{s}\left(\mathrm{m}_{\mathrm{i} 10} \mathrm{~m}_{\mathrm{j} 11}-\mathrm{m}_{\mathrm{i} 11} \mathrm{~m}_{\mathrm{j} 10}\right)-\mathrm{t}\left(\mathrm{m}_{\mathrm{i} 01} \mathrm{~m}_{\mathrm{j} 11}-\mathrm{m}_{\mathrm{i} 11} \mathrm{~m}_{\mathrm{j} 01}\right)
$$

$+\mathrm{r}_{\mathrm{i}} \mathrm{m}_{\mathrm{i}} \mathrm{m}_{\mathrm{j} 11}-\mathrm{r}_{\mathrm{j}} \mathrm{m}_{\mathrm{j}} \mathrm{m}_{\mathrm{i} 11}=\mathrm{m}_{\mathrm{i} 00} \mathrm{~m}_{\mathrm{j} 11}-\mathrm{m}_{\mathrm{j} 00} \mathrm{~m}_{\mathrm{i} 11}$

That is:

$s\left(m_{i 10} m_{j 11}-m_{i 11} m_{j 10}\right)-t\left(m_{i 01} m_{j 11}-m_{i 11} m_{j 01}\right)$ $+\mathrm{r}_{\mathrm{i}} \mathrm{m}_{\mathrm{i}} \mathrm{m}_{\mathrm{j} 11}-\mathrm{r}_{\mathrm{j}} \mathrm{m}_{\mathrm{j}} \mathrm{m}_{\mathrm{i} 11}=\mathrm{m}_{\mathrm{ij}}$

$$
\mathrm{i}=1 \ldots \mathrm{n}, \quad \mathrm{j}=1 \ldots \mathrm{n} \quad \text { and } \mathrm{i} \neq \mathrm{j}
$$

We have $n(n-1) / 2$ equations as format (20) with $n+2$ variables .

Especially, we can use $\mathrm{a}_{0}, \mathrm{~b}_{0}, \mathrm{a}_{0} \mathrm{~b}_{0}, \mathrm{a}_{0}+\mathrm{b}_{0}, \mathrm{a}_{0}-$ $\mathrm{b}_{0}, \mathrm{a}_{0}{ }^{2}, \mathrm{a}_{0}{ }^{3} \ldots$, to get module.

So we can solve the equation set chosen from (11) or (20), if there is no solution or if the $a_{x}$ digits length is not equal to la-lp, or $b_{x}$ digits length is not equal $l b-l p$, then these parts of $a$ and $b$ are contract, and we can discard this branch.

\section{Distributed PARAllel Strategy FOR PRIME FACTORIZATION}

The algorithm in the II section is to find solution path in problem tree. The distributed parallel strategy for prime factorization is that each node computes parts of paths in problem tree. In fig.1, there is one dispatcher which keeps list of free nodes, list of jobs, and create new class of job and dispatches to the free nodes; there are lots of nodes which compute parts of paths in problem tree and report the results or their free status to dispatcher. The description java class for the algorithm is factor class in the following.

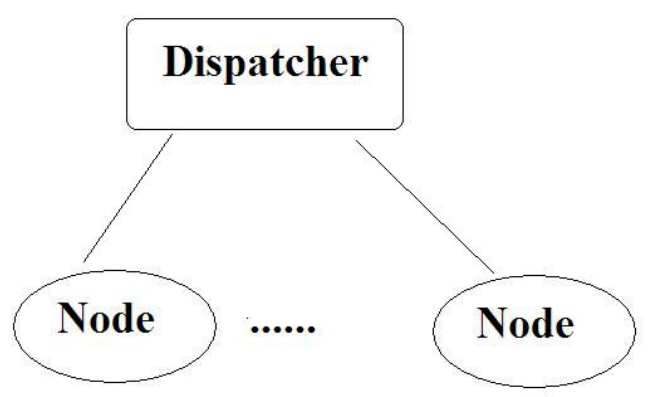

Fig.1 parallel prime factorization

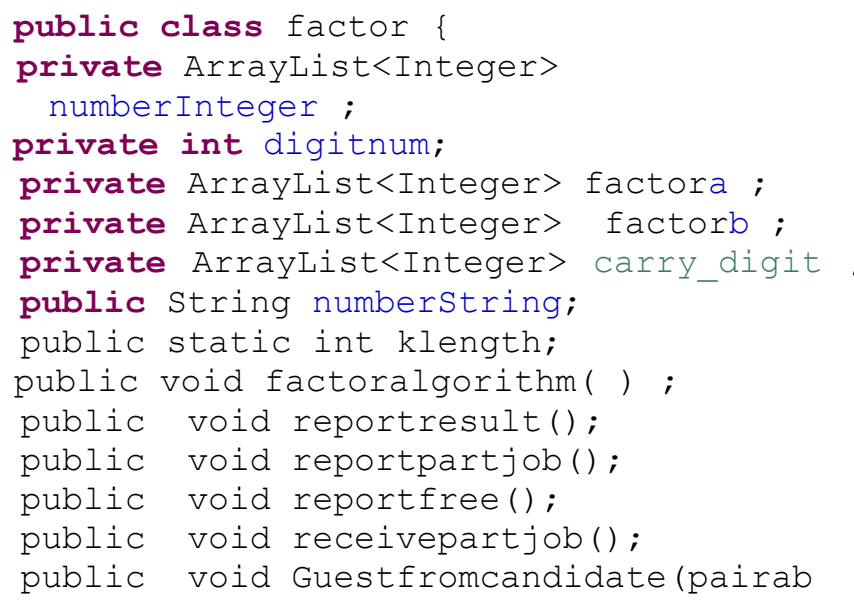
pab) ;

\}

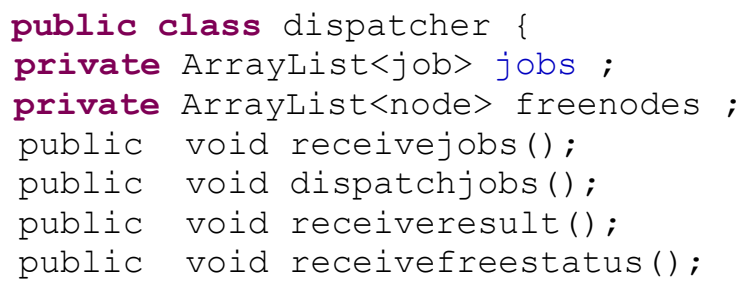

The node uses function Guestfromcandidate from pairset of partial $\mathrm{a}$ and $\mathrm{b}$ factors to select one pair to search and use other function reportpartjob to send jobs to dispatcher.

\section{IMPLEMENTATION OF THE ALGORITHM}

We have implemented the algorithm in Java. The following is output of the factorization of number 6338502007003 .

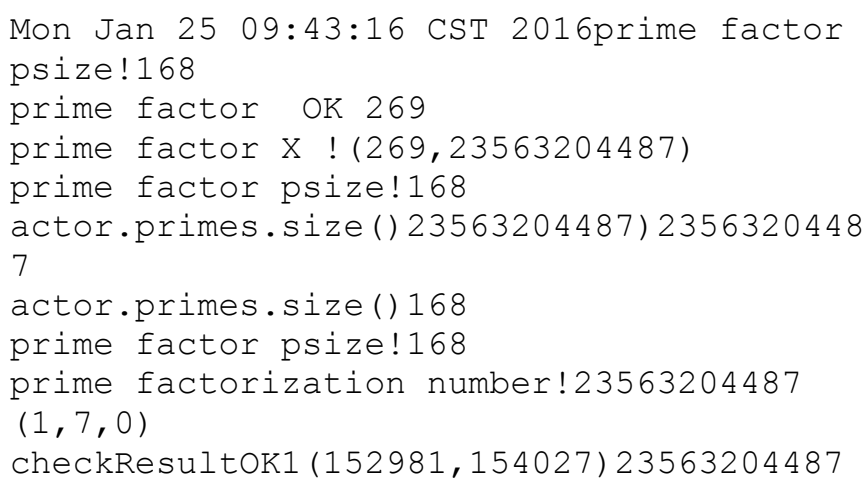


prime factor psize!168

prime factor psize!168

prime factorization number!152981

$(1,1,0)$

$(3,7,2)$

$(9,9,8)$

finished! 152981

prime factor psize!168

prime factor psize!168

prime factorization number!154027

$(1,7,0)$

$(3,9,2)$

finished! 154027

Mon Jan 25 09:43:22 CST 2016

\section{CONCLUSIONS}

In this paper, we present a novel method which construct suitable solution tree by modulo and prunes search branches by equations set and other methods such random, and a parallel strategy using lot of nodes. By try and test, the algorithm and strategy may be potential for factorizing big numbers.

\section{ACKNOWLEDGMENT}

The paper is supported by the project "Hangzhou Qinglan Plan--scientific and technological creation and development (No.20131831K99" of Hangzhou scientific and technological committee. The software copyrights is owned by Hangzhou Domain Zones Technology Co., Ltd., and Chinese patent applied is owned by Hangzhou Domain Zones Technology Company.

\section{REFERENCES}

[1] Ron Rivest, Adi Shamir, and Leonard Adleman. A Method for Obtaining Digital Signatures and Public-Key Cryptosystems, in Communications of the ACM Vol.21 Issue.2, Feb 1978.

[2] A. K. Lenstra and H. W. Lenstra, Jr. (editors), The Development of the Number Field Sieve, Lecture Notes in Mathematics 1554, SpringerVerlag, 1993.

[3] J. M. Pollard, Theorems on Factorization and Primality Testing, Procedings of Cambridge Philosophy Society, 76 (1974), $521\{528$.

[4] P. Shor, Algorithms for Quantum Computation:Discrete Logarithms and Factoring, Proceedings of 35th Annual Symposium on Foundations of Computer Science, IEEE Computer Society Press, 1994,124-134.

[5] R. D. Silverman, The Multiple Polynomial Quadratic Sieve, Mathematics of Computation, 48 (1987), 329-339.

[6] H. C. Williams, A p+1 Method of Factoring", Mathematics of Computation, 39, (1982), 225-234.

[7] Son T. Nguyen, et.al. Integer Factorization Using Hadoop, 2011 Third IEEE International Conference on Coud Computing Technology and Science, 2011, 628-633 